\title{
Functional validation of Winged bean (Psophocarpus tetragonolobus (L.) DC.) anthocyanidin synthase (Wb ANS) gene through virus-induced gene silencing
}

\author{
Vinayak Singh \\ Western University \\ Verandra Kumar \\ National Institute of Plant Genome Research \\ Rayees Ahmad Lone \\ National Botanical Research Institute CSIR \\ Chandra Sekhar Mohanty ( $\square$ cs.mohanti@nbri.res.in ) \\ National Botanical Research Institute CSIR https://orcid.org/0000-0001-9926-4134
}

Research

Keywords: Condensed tannin, anthocyanidin synthase, winged bean, virus-induced gene silencing

Posted Date: August 10th, 2021

DOI: https://doi.org/10.21203/rs.3.rs-768662/v1

License: (c) (i) This work is licensed under a Creative Commons Attribution 4.0 International License.

Read Full License 


\section{Abstract \\ Background}

Histochemical and microscopic observations of various tissues of the underutilized legume winged bean (Psophocarpus tetragonolobus (L.) DC.) indicated that the plant and its various parts are highly infested with condensed tannin (CT). Characterization of CT was carried out through the quantification of its structural-monomeric units catechin and epicatechin. The responsible candidate gene for anthocyanidin synthase (ANS) biosynthesis was identified, phylogenetically mapped and manipulated for lowering the CT-content.

\section{Results}

Virus-induced gene silencing (VIGS) was employed for silencing of WbANS transcript. WbANS-VIGS induction resulted in four-fold decrease in condensed tannin biosynthesis in P. tetragonolobus.

\section{Conclusion}

As condensed tannin adversely affects digestion and considered as an anti-nutrient, so this study might be helpful in future for altering the biosynthesis of condensed tannin by manipulating the ANS-encoding molecular factors.

\section{Background Information}

The oligomers or polymers of flavan-3-ol monomeric units are known as condensed tannins (CTs), these are also known as proanthocyanidins (PAs). CTs are the second most common group of natural phenolics after lignins and are found in the plant-kingdom [1]. The structural complexity of CT endows them with a variety of biochemical properties, including protein interaction, metal chelation and antioxidant function [2]. Catechins and epi-catechins are the simplified monomeric flavanol units for CT formation. They are formed by three enzymes namely:leucoanthocyanidin reductase (LAR), anthocyanidin reducatse (ANR) and anthocyanidin synthase (ANS) in anthocyanin biosynthesis pathway. Anthocyanidin synthase (EC 1.14.11.19) is also known as leucoanthocyanidin dioxygenase. It is a 2oxoglutarate ascorbate dependent oxygenase (LDOX) [3]. ANS is the first and most active enzyme in anthocyanin formation [4]. ANS oxidizes the leucoanthocyanidin molecules to colored anthocyanidins (pelargonidin, cyanidin and delphinidin)[5].Colorless anthocyanidins are formed from the unstable anthocyanidins. Anthocyanidin reductase transforms flavan-3-ols to [(-) epiafzelechin, (-) epicatechin and $(-)$ epigallocatechin] [6]. Arabidopsis thaliana ANS was shown to transform the natural substrate leucoanthocyanidin to cis- and trans-dihydroquercetin and quercetin [7].The biosynthesis of CT oligomers commence by adding an extension unit to a starter unit (catechin or epicatechin) and then adding extension units in a sequential order. The most common monomeric units in CTs are 2, 3-trans (+) 
catechin and 2, 3-cis (-) epicatechin, which have chiral C3 carbon on the C-rings with the opposite stereochemistry. Condensed tannin is formed after polymerization of these monomers [8]. Tea CsLAR gene was expressed ectopically in tobacco, resulting in a higher accumulation of epicatechin than catechin, suggesting that LAR is active in epicatechin biosynthesis [9]. Grape and tea ANRs have been shown to have epimerase activity allowing them to transform anthocyanidin to epi-catechin as well in catechin $[9,10]$. CTs form in the cytoplasm of cells and collect in the vacuoles [11]. CT biosynthesis and aggregation was recorded in a number of species in plant kingdom $[12,13]$ Concerns have been raised about CT transfer from the cytosol to vacuoles and flavan-3-ol monomer polymerization [14]. The CTspecific pathway and the involved structural genes encoding LAR and ANR are yet to be fully elucidated in P. tetragonolobus. However, LAR was first enzyme to be identified in grapevine $[15,16$, and 17$]$ and strawberry [18]. The exact details of the CT polymerization and the functional role of various enzymes involved in this pathway need to be elucidated completely $[19,20]$. Identification of ANS transcript family of $P$. tetragonolobus opened new frontier to study the biosynthetic mechanism of CT. This family of transcripts might have impact on transcriptional regulation in CT biosynthesis in plant-tissues. The initial step for discovery of genes, transcripts and transcription factors responsible for the biosynthesis of CT had been determined with leaf trancriptomics of two contrasting CT-lines of $P$. tetragonolobus [21]. The present activity elucidates the functional role of ANS-encoding gene and its role in modulating the biosynthesis of catechin and epicatechin which is ultimately responsible for CT biosynthesis in the underutilized legume $P$. tetragonolobus. Functional validation of gene-encoding ANS is carried out in the present investigation.

Increased CT-content beyond a certain level reduces the seed-protein quality significantly [22] and disturbs the digestive system of monogastrics. CT is widespread in the plant kingdom. Presence of high levels of CT in tropical legumes limits their use as food and forages and probably the reason for underutilization. One such underutilized tropical legume is winged bean (Psophocarpus tetragonolobus (L.) DC.). CTs are an important factor in the nutritive and dietary quality of many forage crops. It will play wonder if the qualitative improvement of the crop by means of reducing the condensed tannin can be possible. The proposed study will shed light on the biological role of detected ANS transcripts and their probable role in modulating the biosynthesis of condensed tannin in P. tetragonolobus. To analyze and functionally characterize the responsible transcripts [21] virus induced gene silencing (VIGS) was employed through agro-infiltration $[23,24]$. A comparative gene-expression profile and their analysis had been carried out.

\section{Results}

\section{Localization of condensed tannin in different tissues}

Pod, seeds, root and flower plant-tissues of $P$. tetragonolobus at different stages of their maturity were decolorized in absolute ethanol. Subsequent staining of these samples were carried out with $1 \%(\mathrm{w} / \mathrm{v}) 4-$ dimethylaminocinnamaldehyde (DMACA) in absolute ethanol and $6 \mathrm{~N}$ hydrochloric acid in 1:1 ratio. It resulted in the development of a deep-blue color in leaf, seed-coat,T-S of seed flower and Tannin 
accumulation in different stages of seed development (0- 7 days of duration) of P.tetragonolobus seeds (Fig.1.a, b, c, d, and e). The deep-blue colour indicates the presence of condensed tannin in all these tissues.

\section{Establishment of Agrobacterium infection in various explants of $P$. tetragonolobus}

Infection with Agrobacterium tumifaciens was established for further genetic transformation in $P$. tetragonolobus [25]. A. tumifaciens was used for infection through the binary vector pCAMBA1311 which consisted of $\beta$-glucuronidase (GUS) reporter gene (Fig. 2a). Cotyledonary, hypocotyl and epicotyl explants along with young leaf discs and cotyledonery leaf discs were infected with $A$. tumifacienciens. It showed patches of blue colour when subjected to GUS histochemical staining (Fig.2b). These results confirmed A. tumifacienciens infection and transient expression of GUS gene in the transformed explants.

\section{Development of constructs}

The P.tetragonolobus ANS-VIGS construct was created by targeting the PDS (phytoene desaturase) gene and constructing a primer from the conserved region of the P.tetragonolobus transcript. The PDS construct was prepared by PCR based amplification of WB-PDS primer and cloned into VIGS vector (Fig.3a). Due to PDS gene silencing 15 to 20 days after inoculation, syringe-infiltration of this PDS-VIGS construct resulted in bleaching (photo-bleaching) in the systemic leaves (Fig.3b). The bleached areas were initially limited to the veins of the leaves, but the symptoms eventually spread to the majority of the leaf tissues. Then level of PDS was quantified by qRT-PCR (Fig.3C). It resulted in 80 to $90 \%$ lowering of PDS RNA expression in PDS-VIGS lines systemic tissue than in control plants (empty vector).

\section{Silencing of WbANS}

The ANS construct was designed from ANS transcripts. For the creation of the ANS-VIGS construct, WbANS transcript was cloned into VIGS vector. Screening of positive construct was selected through PCR with coat-protein primers (CP 351bp) of virus vector and ANS (anthocyanidin 162bp) gene specific primers of $P$. teragonolobus (Fig 4a). Positive ANS-VIGS lines were picked after 4 weeks of transformation using PCR with CP unique primers (Fig.4b). Using ANS gene specific primers, qRT-PCR was performed and it was reported that the transcript level of the VIGS plants were reduced. When compared to control plant, the ANS1-VIGS line showed a substantial reduction of (up to $80 \%$ ) of the constituents of CT (Fig. $5 a)$.

\section{Condensed tannin estimation through vanillin- $\mathrm{HCl}$ assay}

Quantitative estimation of condensed tannin was determined in both silenced and control plant of $P$. tetragonolobus. A calibration curve of catechin-equivalent standard curve was obtained and expressed in $\mathrm{mg} / \mathrm{g}$ dry weight. All assays were carried out in triplicates. The total condensed tannin content was estimated by vanillin- $\mathrm{HCl}$ assay. In control plant, the value was $2.6 \mathrm{mg} / \mathrm{gram}$ of dry weight of leaf sample and in case of VIGS-silenced line of P.tetragonolobus the value reduced to $0.7 \mathrm{mg} / \mathrm{g}$ of dry weight of leaf 
tissues (Fig. 5B). So, a decrease of 73\% in condensed tannin cotent was reported in VIGS-line of $P$. tetragonolobus.

\section{Silencing of ANS transcripts decreased the accumulation of catechin and epicatechin}

Catechin and epicatechin showed higher quantity in control plant as compared to VIGS silenced $P$. tetragonolobus. The quantity was estimated through standard HPLC (Fig.6a). The control plant contained $3.8 \mathrm{mg}$ of catechin per gm of dry weight of leaf sample. But, in case of the VIGS-silenced line the concentration of catechin decreased up to $0.28 \mathrm{mg} / \mathrm{g}$. It showed that, catechin concentration decreased up to $92 \%$ after silencing of ANS transcript. Same is in the case of epicatechin concentration of VIGS line which decreased up to $71 \%$ compared to the control plant (Fig.6b).

\section{Confocal microscopic analysis of the VIGS-induced P.tetragonolobus}

The concentration of condensed tannin in both VIGS as well as control $P$. tetragonolobus was visualized by confocal microscopy after Oregon green staining. Transverse section of the leaves of both the lines was observed under microscope. Integrated hexagonal network of cells without any deformities or abnormalities were observed in control plant but in case of VIGS-line, there was breakage in hexagonal networking of cells (Fig.7a). Oregon green dye formed complex with condensed tannin and the confocal microscopic images showed green fluorescence on interaction. Image $\mathrm{J}$ software was used to measure the fluorescence levels of the control and VIGS P. tetragonolobus (http://rsbweb.nih.gov/ij/) and it was reported that in the VIGS-line of $P$. tetragonolobus, the florescence level decreased significantly compared to the control plant (Fig.7b). This result confirmed that the silencing of anthocyanidin synthase gene in P.tetragonolobus have a regulatory role on condensed tannin biosynthesis of $P$. tetragonolobus.

\section{Phylogenetic analysis of ANS}

Phylogenetic analysis of the conserved ANS protein sequences were carried out among 114 plant species. It grouped them into four well defined clades based upon their proximity with each other. The phylogenetic tree was generated on the basis of their likelihood and similarity upon analysis on MEGA-X software. Four clades were formed indicating the similarity among the plant-taxa. In the first-clade, $P$. tetragonolobus showed closeness with spinach oleraceae and out group in the clade is fragararia esculatum. In clade two P.tetragonolobus is closed to carathamus tintctorius and oryza officinalis (Fig.8).

\section{Discussion}

The nutritive benefit of the browse shrub mulga is substantially decreased when CT reaches (8-10) \% of dietary dry content [26]. P. tetragonolobus (L.) DC. is one of the plants of agricultural importance and contain high protein and almost all parts of the plant are edible. It has high nutritive value in terms of protein and fatty oil content [27]. But, presence of anti-nutrients is one of the reasons of its lesser use. CT is one of the anti-nutrient present in P. tetragonolobus. 
Localization, qualitative and quantitative estimation of condensed tannin was carried out by using DMACA staining and Vanillin- $\mathrm{HCl}$ assay respectively in different tissues of the P.tetragonolobus. DMACA staining exhibited a high level of susceptibility to flavonols, since epicatechin is 1,000 times more resilient than the structurally similar p-dimethylaminobenzaldehyde [28]. To classify spatial patterns of condensed tannin aggregation in different plant tissues, histochemical staining of plant tissues with DMACA is commonly used. The formation of CTs in tracheophyta inside the thylakoid-derived organelles, the tannosomes was proposed by Brillouet et al.[11]. Multiple membrane-bound shuttles transport tannosomes from the plastid to the vacuole.

HPLC analysis reported flavan-3-ol (catechin) as a general secondary metabolite in seeds and various tissues of this plant. Condensed tannin gets highly accumulated in the ovary, pod, root and fleshy part of the outer seed coat of the plant (Fig. 1). Microscopic observations and histochemical studies indicated that seeds are the major sites of accumulation of CTs and their localization (Fig. 1e). HPLC study of P.tetragonolobus(L.) DC seeds revealed the existence of flavan-3-ols (catechins) as a general secondary metabolite, as well as catechin, epicatechin, and various dimeric flavan-3-ols as predominant polyphenol (Fig. 6).

As anthocyanidin synthase is the enzyme for synthesis of condensed tannin in P.tetragonolobus. In the evolutionary analysis, it has been observed that the WbANS proteins are closely related to Spinacia. P.tetragonolobus protein had been shown similarity with Glycine max. It has been revealed that ANS gene was evolved early in evolution, which might be playing a significant role in the biosynthesis of condensed tannin among the different members of plant-kingdom.

Virus-induced gene silencing (VIGS) is a simple method of inhibiting gene expression in order to determine the function of a specific gene [29]. The preparation of an efficient VIGS construct for ANS transcript was carried out in the present study. The silencing by ANS within the plant is influenced by environmental conditions as well as the process of inoculation [30,31]. The expressed genes were used for optimization of gene silencing [32,33]. The PDS-VIGS gene silencing of the PDS gene in chilli pepper leaves resulted in the repression of flavonoid biosynthesis. Photobleaching became a problem for the virus-infected silenced plants [34].WB-PDS was effectively silenced using PDS from transcript data of P.tetragonolobus as similar efficiency was found among the members of Solanaceaeous with TRV and PDS constructs [35].The ANS-VIGS mechanism has been used to down-regulate anthocyanidin synthase in order to gain a better understanding of their function in plants.

To get a complete picture of understanding of the result of the ANS transcript-silencing on condensed tannin biosynthetic pathway, qPCR analysis of different silenced plants with gene-encoding ANS was performed. The expression level of ANS gene was decreased in silenced plants. The down-regulated silenced lines accumulated low amount of catechin and epicatechin in the leaves. From these results, it may be concluded that, the accumulation of condensed tannin increases due to the increased expression of ANS encoding gene in the biosynthetic pathway of condensed tannin. The HPLC analysis of silenced lines indicated that the catechin and epicatechin concentration was lowered. Previous studies about the 
condensed tannin showed that, synthesis of condensed tannin started in chloroplast and gets accumulated in the vacuole of cell [11]. Accumulation of condensed tannin was confirmed through Oregon green dye and it showed that the accumulation to decreases with the silencing ANS-encoding genes of P.tetragonolobus.

\section{Conclusion}

An efficient protocol for virus induced gene silencing is developed in P.tetragonolobus through TRV vector. To confirm the down-regulation of ANS transcript, in winged bean, condensed tannin estimation through vanillin- $\mathrm{HCl}$ assay was performed in control as well as VIGS plants. Decreased level of condensed tannin in silenced plant was reported. Approximately, 73\% of condensed tannin was decreased in VIGS line of $P$. tetragonolobus. The monomeric unit of CT i.e. catechin and epicatechin was quantified through HPLC in both control as well as silenced plants. The catechin concentration decreased up to $92 \%$ after silencing the ANS transcript. Similarly, epicatechin concentration decreased up to $71 \%$ compared to the control plant. Localization of condensed tannin in silenced and control plant was observed on confocal microscope to decrease, so anthocyanidin synthase transcript was determined as the potential transcript for condensed tannin biosynthesis. As virus induced gene silencing provided transient line of $P$. tetragonolobus. It will further open up ways for administering various editing technologies for production of stable line with lowered condensed tannin-level in $P$. tetragonolobus. This will help in developing new strategies for better utilization of ANS transcript for creating protein-fortified $P$. tetragonolobus with reduced condensed tannin content and from underutilization to commercial utilization.

\section{Materials And Method}

\section{Plant Material}

The ICAR-National Bureau of Plant Genetic Resources (NBPGR) India supplied the winged bean seeds (Psophocarpus tetragonolobus) and these seeds were cultivated in botanic garden of CSIR-National Botanical Research Institute in Lucknow, India for further use.

\section{Histochemical staining of different plant tissues}

The staining for condensed tannin of root, pod, flower and seeds of $P$. tetragonolobus was carried out through ethanol: $\mathrm{HCl} 6 \mathrm{M}(1: 1)$ ratio, carrying $0.1 \%$ dimethyl ammino cinnamaldehyde (DMACA) (Sigma-Aldrich) (w/v) for about 3 to 6 min and washed thrice with water. All other plant organs were stained for $2 \mathrm{~h}$ and flowers were stained for only 20 minutes. After staining, the tissues were visualized through microscope and photographed at an appropriate magnification.

\section{Transcript-VIGS construct preparation}

WbANS and WbPDS transcript sequences were extracted from de novo leaf-transcriptome data of comparative condensed-tannin lines of P.tetragonolobus [21]. Effective region of the transcript was selected by SGN-VIGS online tool [36]. These transcripts were amplified using gene specific primers (Supplementary Table S1). The purified fragment was cloned into PTRV1 and PTRV2 vector (procured from TAIR). It was digested with XbaI and SacI restriction enzymes (NEB). The digested product of both the insert and vector were ligated with $1 \mu \mathrm{l}$ of T4 DNA ligase (NEB) [31,37] the ligated constructs of both the transcripts were transformed into the DH5 $\alpha$ strain of E. coli. Amplification of replicase (562 bp), coat protein (351 bp), WbPDS $(210 \mathrm{bp})$ and WbANS (162 bp) were carried out through the basic primers. They were tested in 
the colonies and were confirmed for positive construct through gene specific PCR amplification.

\section{Plant growth and agro-infiltration}

The freshly germinated P.tetragonolobus (4 leaf stage) was subjected to agro-infiltration with TRV construct. WbANS::TRV2 and WbPDS::TRV2 constructs were then transformed into GV3101 Agrobacterium tumefaciens strain. Positive transformants were chosen using colony PCR in Luria-Bertani agar medium (25 mg rifampicin, $50 \mathrm{mg}$ gentamycin, $50 \mathrm{mg}$ kanamycin per litre). The Agrobacterium strains were cultured in simple $5 \mathrm{ml}$ primary cultures and were injected from individual colonies on plates two days before infiltration and grown for 16 hours at $28^{0} \mathrm{C}$. The primary culture was injected with $20 \mathrm{ml}$ of secondary culture, which was cultivated for (5-6) hours. Centrifugation at $3000 \times \mathrm{g}$ for 5 minutes at room temperature was used to extract the culture. The pellet was regenerated with the same quantity of induction buffer, $10 \mathrm{mM}$ MES (pH 5.5) and $200 \mathrm{M}$ acetosyringone and was incubated at $28^{\circ} \mathrm{C}$ at $80 \mathrm{rpm}$ for (3-4) hour. The culture was then pelleted at 3000× $\mathrm{g}$ and resuspended in $5 \mathrm{mM} \mathrm{MES} \mathrm{(pH}$ 5.5) penetration buffer with $\mathrm{OD}_{600}$ set to (0.8-0.9). The cultures were combined at a ratio of $1: 1(\mathrm{v} / \mathrm{v})$. The abaxial side of the lower leaves was inoculated with TRV1 + ANS::TRV2 Agrobacterium culture using a needleless syringe. TRV1:: TRV2 infiltration in the plants acted as control (empty vector).The inoculated plants in the greenhouse were analysed during the observations [31]

\section{RNA isolation and RT-PCR}

RNA isolation kit (Sigma-Aldrich) was used to extract total RNA from the upper leaves of 3week-infiltered plants. RNase-free DNaseI treatment (Ambion) was provided to the extracted RNA. Approximately, $5 \mathrm{~g}$ of total RNA and oligo (dT) primers were used for first-strand complementary DNA synthesis. Step One Plusq RT-PCR System was used to perform the PCR (Applied Biosystems 7500). Supplementary Table S1 lists the primers used in qRT-PCR. On qRT-PCR study, three separate biological replicates and two technological replicates for each biological replicates were used for validation.

\section{Multiple-sequence alignment and phylogenetic analysis of anthocyanidin synthase gene}

MUSCLE software was employed for the sequence alignment of protein sequences of the ANS gene from transcript data of $P$. tetragonolobus. All protein databases of ANS was created and saved in the ClustalW format. The phylogenetic analysis was carried out at 1000 bootstrap replications using the MEGA 6.0 software [38]. The Poisson model approach was used to build an unrooted neighbor-joining tree as well as a minimum evolution tree using the same alignment file.

\section{Comparative quantification of CT}

The overall CT-value was measured using the colorimetric method of the modified vanillinhydrochloric acid assay in both VIGS and control $P$. tetragonolobus developed by Hagerman et al. [39]. Dry-leaf powder ( $50 \mathrm{mg}$ each) was suspended in $1 \mathrm{ml}$ methanol and centrifuged. Approximately, $5 \mathrm{ml}$ of active vanillin- $\mathrm{HCl}$ reagent was added to the supernatant (one part vanillin solution and one part $8 \% \mathrm{HCl}$ solution in methanol) incubated for 20 minutes at $30^{\circ} \mathrm{C}$. The absorbance of the solution was recorded at $500 \mathrm{~nm}$ by spectrophotometer (Shimadzu, UV-1601).

\section{Analysis of monomeric components of condensed tannin in P. tetragonolobus}

HPLC analysis for catechin, epicatechin and VIGS line of $P$. tetragonolobus leaf was carried out on phenomenex Luna RP-C 18 column using high pressure liquid chromatography. The ultra violet (Shimadzu LC-10A, Japan) fitted two fold pump LC-10AT with binary system with UV detector SPD-10A at 254 nanometer, rheodyne injection valve with a $20 \mathrm{ml}$ loop on phenomenex Luna RP-C 18 (4.6 X $250 \mathrm{~mm}$ with $5 \mathrm{~mm}$ pore-size) preceded with column guard of same chemistry. Shimadzu's class VP series programme was used to incorporate the data. HPLC analysis of the dried powdered leaf-tissues of P.tetragonolobus was performed to produce metabolic profiles. 
The co-cultivated explants were rinsed with sterile water containing cefotaxime $\left(0.25 \mathrm{mgl}^{-1}\right) \mathrm{and}^{-}$ were blotted on filter-paper. The GUS-histochemical staining was carried out according to the earlier report with minor modifications [40]. These explants were incubated in GUS staining solution containing $1.0 \mathrm{mM}$ of bromo-chloro-indolyl solution (X-Gluc), $0.5 \mathrm{mM}$ ferrocyanide in $50 \mathrm{mM}$ phosphate buffer $\left(\mathrm{pH} \mathrm{7.0)}\right.$ ) at $37^{\circ} \mathrm{C}$ overnight. The GUS stained explants were rinsed with sterile distilled water and treated with $70 \% \mathrm{EtOH}$ for de-coloration of chlorophyll.

\section{Confocal analysis}

For condensed tannin deposition assay through Oregon green 488 staining was performed. Then $1 \mathrm{mg}$ Oregon green was diluted with $5 \mathrm{ml}$ PBS buffer. The infected leaves were incubated in $1 \mathrm{ml}$ solution at room temperature for (15-30) minutes and washed with PBS solution for 15 minute. The leaves which were stained were imaged using a Carl Zeiss LSM 510 META confocal microscope with a 20x Plan-apochromate lens. Excitation was sustained with a $519 \mathrm{~nm}$ diode laser and emission was reported at in $499 \mathrm{~nm}$ band pass filter.

\section{Statistical analysis}

The Graph Pad Prism was employed for the statistical analysis

\section{Declarations}

\section{Acknowledgments}

Director, CSIR-NBRI is duly acknowledged for proving the basic infrastructural facility to carry out this work

\section{Authors contribution}

VS Conceptualization, Formal analysis, Writing, review \& editing. V RFormal analysis, Confocal analysis and Validation. RL: Resources, Validation, Writing review \& editing. C S M Conceptualization, Project administration, Funding acquisition, Supervision, Validation; Writing review \& editing. All authors read and approved the final manuscript.

\section{Funding}

CSIR- Council of Scientific and Industrial Research. Ministry of Science and technology, Govt. of India, supported the work

\section{Ethics approval and consent to participate}

Local, National and International guidelines were followed in this study with virus induced gene silencing in plants.

\section{Consent for publication}

Not applicable.

\section{Competing Interest}


The authors declare that they have no known competing financial interests or personal relationships that could have appeared to influence the work reported in this paper.

\section{Author details}

${ }^{1}$ CSIR-National Botanical Research Institute (CSIR-NBRI), Rana Pratap Marg, Lucknow-226001, India

${ }^{2}$ Academy of Scientific and Innovative Research (AcSIR), Ghaziabad -201002, India . ${ }^{\#}$ Corresponding author,Plant Genetics and Improvement Division,CSIR-National Botanical Research Institute,Lucknow-226 001, Uttar Pradesh,India

\section{References}

1.Santos-Buelga C, Scalbert A. Proanthocyanidins and tannin-like compounds- nature, occurrence, dietary intake and effects on nutrition and health. Journal of the Science of Food and Agriculture. 2000;80: 10941117.

2.Karamac, M.Chelation of $\mathrm{Cu}$ (II), Zn (II) and Fe (II) by tannin constituents of selected edible nuts. Int. J. Mol. Sci. 2009 ; 10, 5485-5497

3.Nakajima J,Tanaka Y, Yamazaki, M, Saito, K. Reaction Mechanism from Leucoanthocyanidin to Anthocyanidin 3-Glucoside, a Key Reaction for Coloring in Anthocyanin Biosynthesis. Journal of Biological Chemistry.2001; 276(28), 25797-25803.

4.Pelletier, MK, Murrell, JR, Shirley,BW.Characterization of Flavonol Synthase and Leucoanthocyanidin Dioxygenase Genes in Arabidopsis (Further Evidence for Differential Regulation of "Early" and "Late" Genes). Plant Physiology.1997; 113(4), 1437-1445.

5.Saito K,Kobayashi M,Gong Z,Tanaka Y,Yamazaki M.Direct evidence for anthocyanidin synthase as a 2oxoglutarate-dependent oxygenase: molecular cloning and functional expression of cDNA from a red forma of Perillafrutescens. The Plant Journal .1999;17(2), 181-189.

6.Xie, DY, Sharma, SB, Paiva NL, Ferreira D, Dixon RA. Role of Anthocyanidin Reductase, Encoded by BANYULS in Plant Flavonoid Biosynthesis. Science.2003; 299(5605), 396-399.

7.Welford RWD, Turnbull JJ, Claridge TDW, Schofield C J, Prescott, AG. Evidence for oxidation at C-3 of the flavonoid C-ring during anthocyanin biosynthesis. Chemical Communications. 2001; (18), 18281829.

8. Harding SA, Xue LJ, Du L, Nyamdari B, Lindroth RL, Sykes R, Davis MF, Tsain C.Condensed tannin biosynthesis and polymerization synergistically condition carbon use, defense, sink strength and growth in Populus. Tree Physiology.2014; 34, 1240-1251. 
9.Pang Y, AbeyFe IS, He J, He X, Huhman D, Mewan KM.Functional characterization of proanthocyanidinpathway enzymes from tea and their application for metabolic engineering. Plant Physiol. $2013 ; 161,1103-1116$.

10.Gargouri M, Chaudière J, Manigand C, Maugé C, Bathany K,Schmitter JM, Gallois B.The epimerase activity of anthocyanidin reductase from Vitis vinifera and its region specific hydride transfers. BiolChem.2010; 391:219-227.

11.Brillouet JM, Romieu C, Schoefs B, Solymosi K, Cheynier V, Fulcrand H,Conéjéro, G. The tannosome is an organelle forming condensed tannins in the chlorophyllous organs of Tracheophyta.Annuals of Botany. $2013 ; 112(6), 1003-1014$

12. Matsui K, Tanaka H,Ohme-Takagi M.Suppression of the biosynthesis of proanthocyanidin in Arabidopsis by a chimeric PAP1 repressor. Plant Biotechnology Journal.2004 ; 2(6), 487-493.

13. Liu CM, Ma JQ, Liu, SS, Zheng GH, Feng ZJ, Sun JM. Proanthocyanidins improves lead-induced cognitive impairments by blocking endoplasmic reticulum stress and nuclear factor-KB-mediated inflammatory pathways in rats. Food and Chemical Toxicology. $2014 ; 72,295-302$

14.Zhao J, PangY, Dixon RA.The Mysteries of Proanthocyanidin Transport and Polymerization.Plantphysiology.2010; 153(2), 437-443.

15.Bogs J, Downey MO, Harvey JS, Ashton AR, Tanner TG, Robinson SP. Proanthocyanidin synthesis and expression of genes encoding leucoanthocyanidin reductase and anthocyanidin reductase in developing grape berries and grapevine leaves.Plant physiology. $2005 ; 139(2), 652-663$.

16.Pfeiffer J, Kühnel C, Brandt J, Duy D, Punyasiri PA N, Forkmann G, Fischer TC.Biosynthesis of flavan 3 -ols by leucoanthocyanidin 4-reductases and anthocyanidin reductases in leaves of grape (Vitis vinifera L.), apple (Malus x domesticaBorkh.) and other crops. Plant Physiology and Biochemistry .2006. ; 44(5-6), 323-334.

17.Maugé C, Granier T, d' Estaintot B L, Gargouri M, Manigand C, Schmitter JM ,Gallois B.Crystal Structure and Catalytic Mechanism of Leucoanthocyanidin Reductase from Vitisvinifera. Journal of Molecular Biology.2010;397(4), 1079-1091.

18.Almeida JRM, D'Amico E, Preuss A, Carbone F, de Vos CH R, Deiml B, Rosati C .Characterization of major enzymes and genes involved in flavonoid and proanthocyanidin biosynthesis during fruit development in strawberry(Fragaria ananassa). Archives of Biochemistry and Biophysics.2007;465(1), $61-71$.

19.Dikson R, Xie D, Sharma SB. Proanthocyanidins - a final frontier in flavonoid research. New Phytologist. 2005;165(1):9-28. 
20.Lepiniec L, Debeaujon I, Routaboul JM, Baudry A, Pourcel L, Nesi N, Caboche M. Genetics and biochemistry of seed flavonoids.Annual Review of Plant Biology.2006; 57(1), 405-430.

21.Singh V, Goel R, Pande V, Asif, MH, Mohanty C.S. De novo sequencing and comparative analysis of leaf transcriptomes of diverse condensed tannin-containing lines of underutilized Psophocarpus tetragonolobus (L.) DC. Scientific Reports. 2017 ; 7(1).

22. Hagerman AE, Riedl KM, Jones G A, Sovik KN, Ritchard NT, Hartzfeld PW, Riechel T L. High Molecular Weight Plant Polyphenolics (Tannins) as Biological Antioxidants. Journal of Agricultural and Food Chemistry.1998; 46(5), 1887-1892.

23.Burch-Smith TM, Anderson JC, Martin GB, Dinesh-Kumar SP. Applications and advantages of virusinduced gene silencing for gene function studies in plants. The Plant Journal.2004;39(5), 734-746.

24.Robertson, D. vigs vectors for gene silencing: many targets, many tools. Annual review of plant biology. 2004 ; 55(1), 495-519.

25. Singh V, Chauhan NS, Singh M, Idris A, Madanala R, Pande V, Mohanty CS (2014). Establishment of an efficient and rapid method of multiple shoot regeneration and a comparative phenolics profile in vitro and greenhouse-grown plants of Psophocarpus tetragonolobus (L.) DC. Plant Signaling and Behavior 9: 10 .

26. Pritchard DA, Stocks DC, O'Sullivan BM, Martins PR, Hurwood IS, O'Rourke PK. The effect of polyethylene glycol (PEG) on wool growth and live weight of sheep consuming a Mulga (Acacia aneura) diet. Proc. Aust. Soc. Anim. Prod. 1988 ;17: 290-293.

27.Mohanty CS, Pradhan RC, Singh V, Singh N, Pattanayak R, Prakash O, Rout P K. Physicochemical analysis of Psophocarpus tetragonolobus (L.) DC seeds with fatty acids and total lipids compositions. Journal of Food Science and Technology. 2014 ;

28. Treutter D. Chemical reaction detection of catechins and proanthocyanidins with 4dimethylaminocinnamaldehyde. Journal of Chromatography. $1989 ; 467,185-193$.

298.Brigneti G, Martín-Hernández AM, Jin H, Chen J, Baulcombe DC, Baker B, Jones JDG. Virus-induced gene silencing in Solanum species. The Plant Journal.2004; 39(2), 264-272

30.Broderick SR, Jones M.L.,.An Optimized Protocol to Increase Virus-Induced Gene Silencing Efficiency and Minimize Viral Symptoms in Petunia. Plant Molecular Biology Reporter.2013 ; 32(1), 219-233.

31.Singh G, Tiwari M, Singh SP, Singh S, Trivedi PK, Misra P. Silencing of sterol glycosyltransferases modulates the withanolide biosynthesis and leads to compromised basal immunity of Withaniasomnifera. Scientific Reports.2016;6(1). 
32.Ruiz MT. Initiation and Maintenance of Virus-Induced Gene Silencing. THE PLANT CELL.1998; 10(6), 937-946

33.Sha A, Zhao J, Yin K, Tang Y, Wang Y, Wei X. Virus-based microRNA silencing in plants. Plant Physiol. 2014;164 36-47.

34.Zhang Z, Li DW, Jin JH, Yin YX, Zhang HX, Chai WG, Gong ZH. VIGS approach reveals the modulation of anthocyanin biosynthetic genes by CaMYB in chili pepper leaves. Frontiers in Plant Science. $2015 ; 6$.

35.Senthil-Kumar M, Mysore KS.Virus-induced gene silencing can persist for more than 2 years and also be transmitted to progeny seedlings in Nicotiana benthamiana and tomato. 2011 ;

36.Fernandez-Pozo N, Rosli HG, Martin GB, Mueller LA. The SGN VIGS Tool: User-Friendly Software to Design Virus-Induced Gene Silencing (VIGS) Constructs for Functional Genomics. Molecular Plant. 2015; 8(3), 486-488.

37.Senthil-Kumar, M., Mysore, K. S.,.Tobacco rattle virus-based virus-induced gene silencing in Nicotianabenthamiana. Nature Protocols.2014; 9(7), 1549-1562. 37.Wang J, Wang X, Geng S, Singh SK, 38.Wang Y, Pattanaik S, Yuan L. Genome-wide identification of hexokinase gene family in Brassica napus. structure, phylogenetic analysis, expression, and functional characterization. Planta.2018; 248(1), 171-182.

39.Hagerman AE, Butler LG.The specificity of proanthocyanidin-protein interactions.the journal of biological chemistry. 1981 ; Vol. 256, No. 9, Issue of May 10, PP. 4444-4497.19.

40.Jefferson RA.Assaying chimeric genes in plants: The GUS gene fusion system. Plant Molecular Biology Reporter.1987; 5(4), 387-405

\section{Figures}



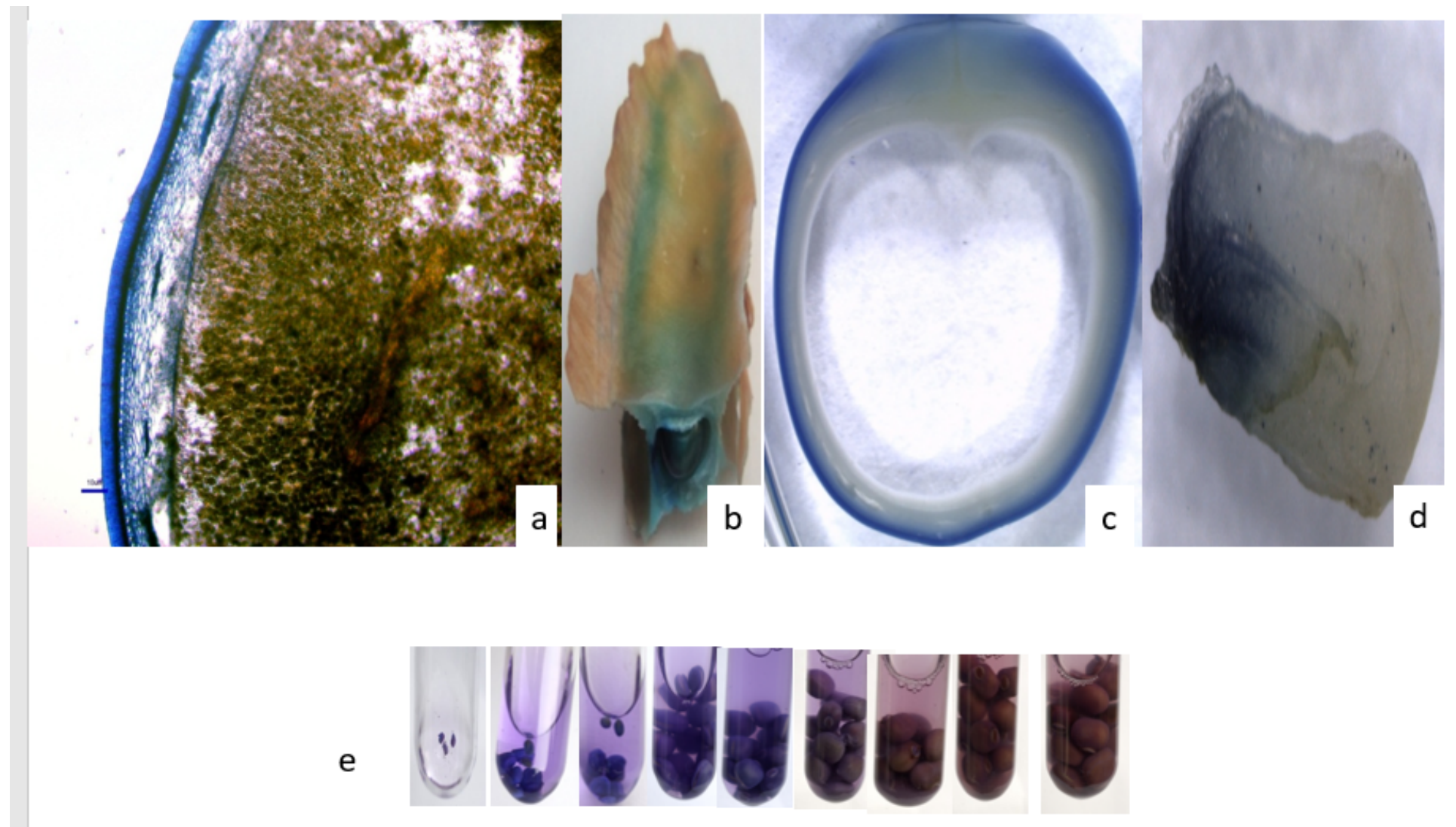

Figure 1

Localization of condensed tannin in tissues of P.tetragonolobus through DMACA staining (a-leaf ,b-seed with pod, c- T.S. of seed containing seed coat.d-staining of flower,e-Tannin accumulation in different stages of seed development ( 0 - 7 days of duration) of P.tetragonolobus seeds 

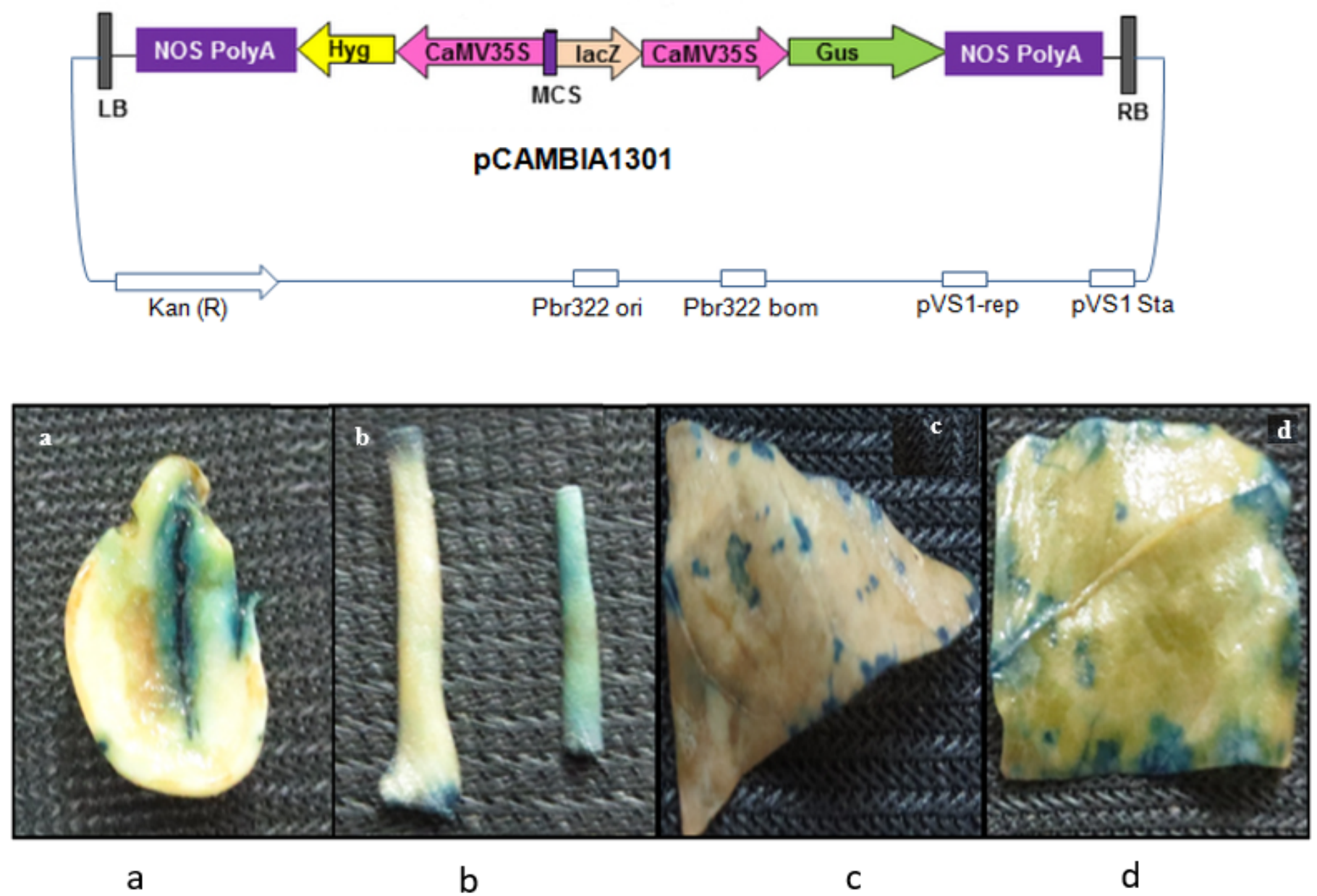

Figure 2

Histochemical GUS staining of various explants after A. tumefacience infection; GUS staining is seen as blue coloured patches on various explants, a. Cotyledons explants; b. Hypocotyl and epicotyls; c. Young leaf disc; $d$. Cotyledonery leaf disc. 
(a)

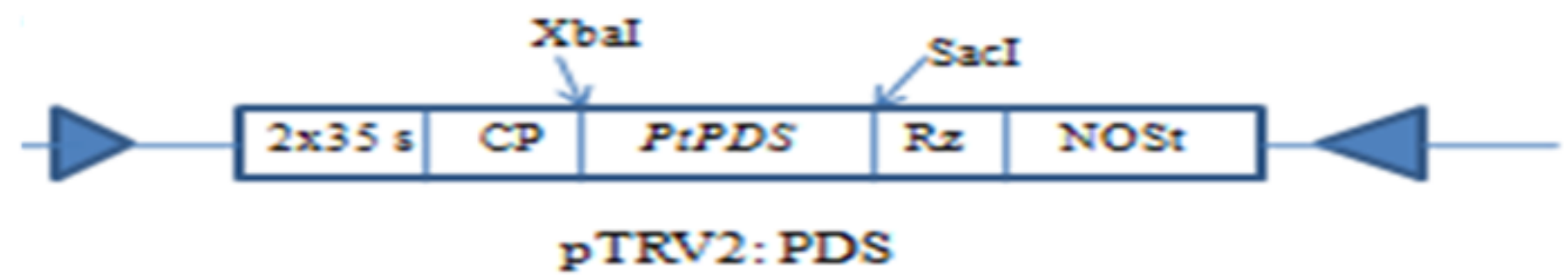

(b)
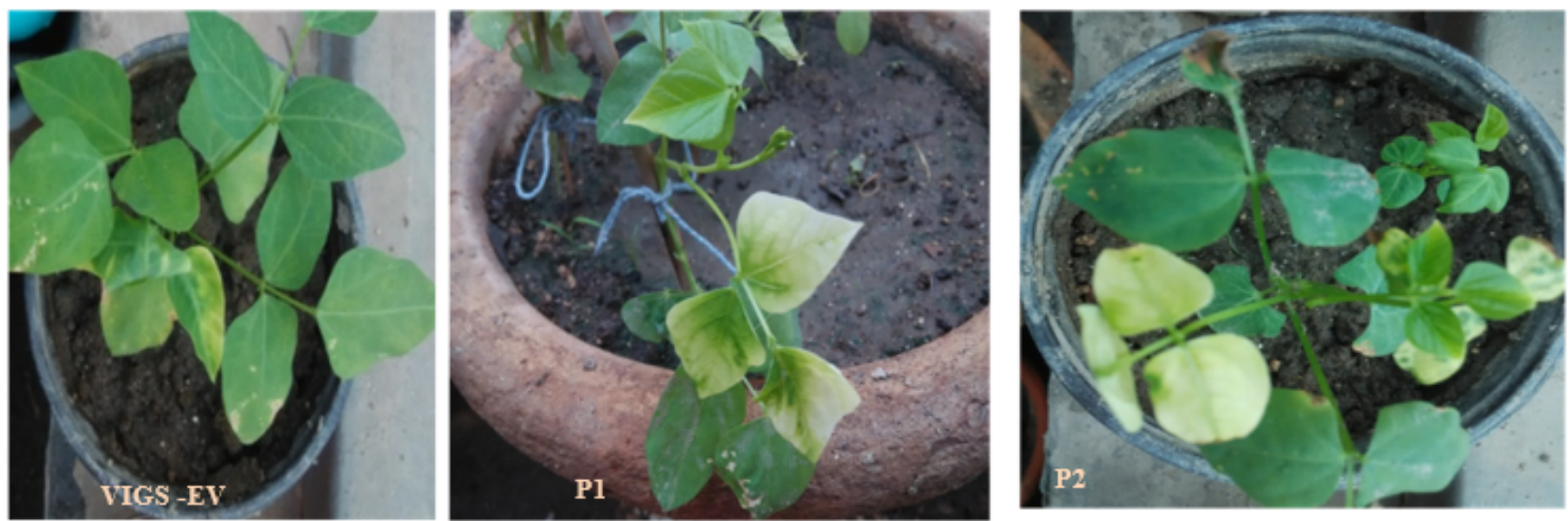

(c)

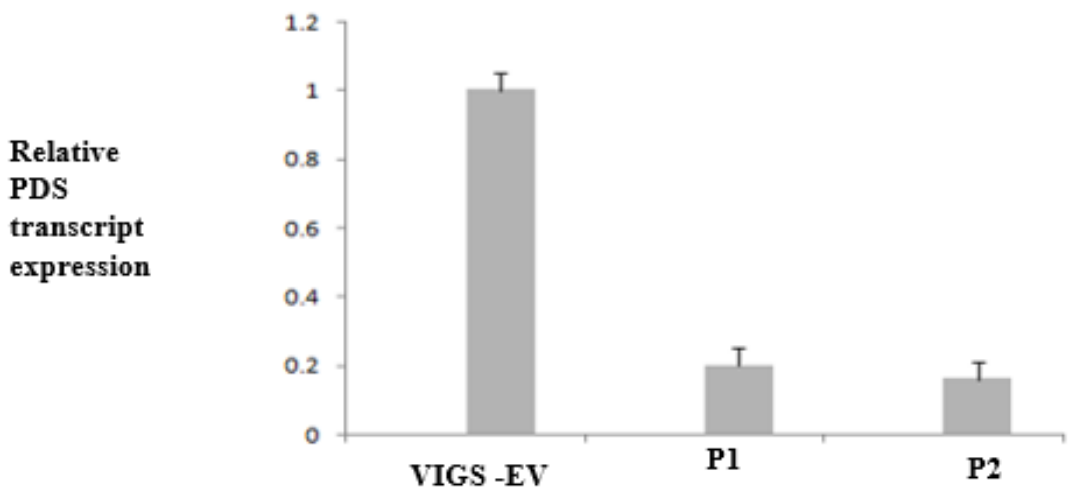

\section{Figure 3}

(a) systemic construct of TRV2 :PDS .(b) VIGS-EV (control plant) and VIGS PDS plant (P1 and P2) positive phenotypic change in leave of silenced plant after 20 day post infiltration , (C) Real time expression of VIGS-PDS normalization with 18s rRNA 
a

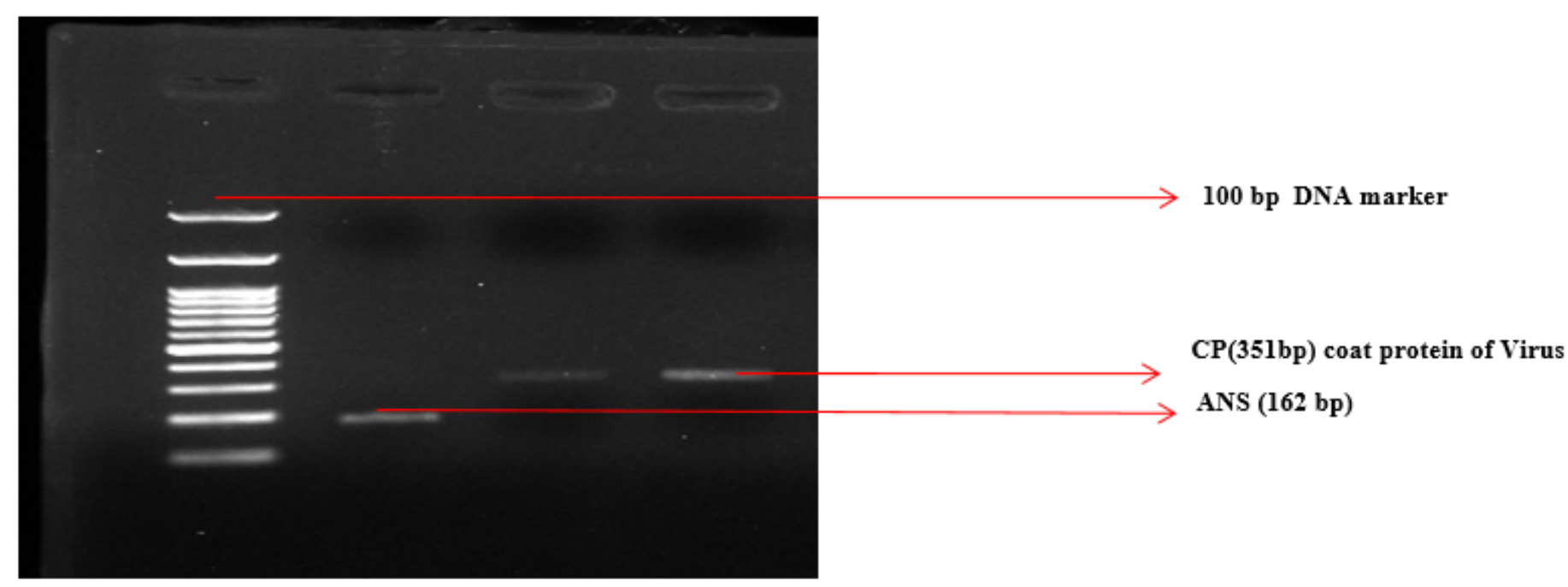

b
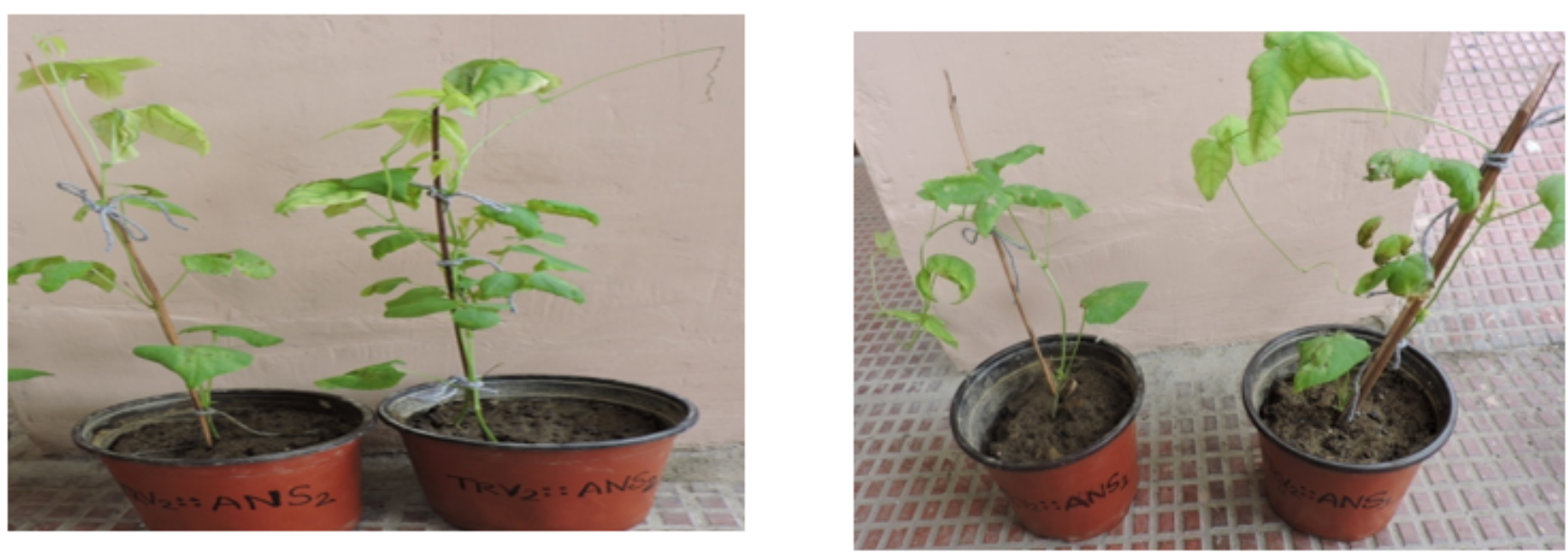

Figure 4

(a ) Gel image showing the ANS (162bp) and CP (351 bp)gene specific primer for screening of positive construct of ANS (Anthocyanidin synthase). (b) Positive selection of VIGS-ANS plant: positive plant selected through coat protein primer of virus (351 bp). 
(a)

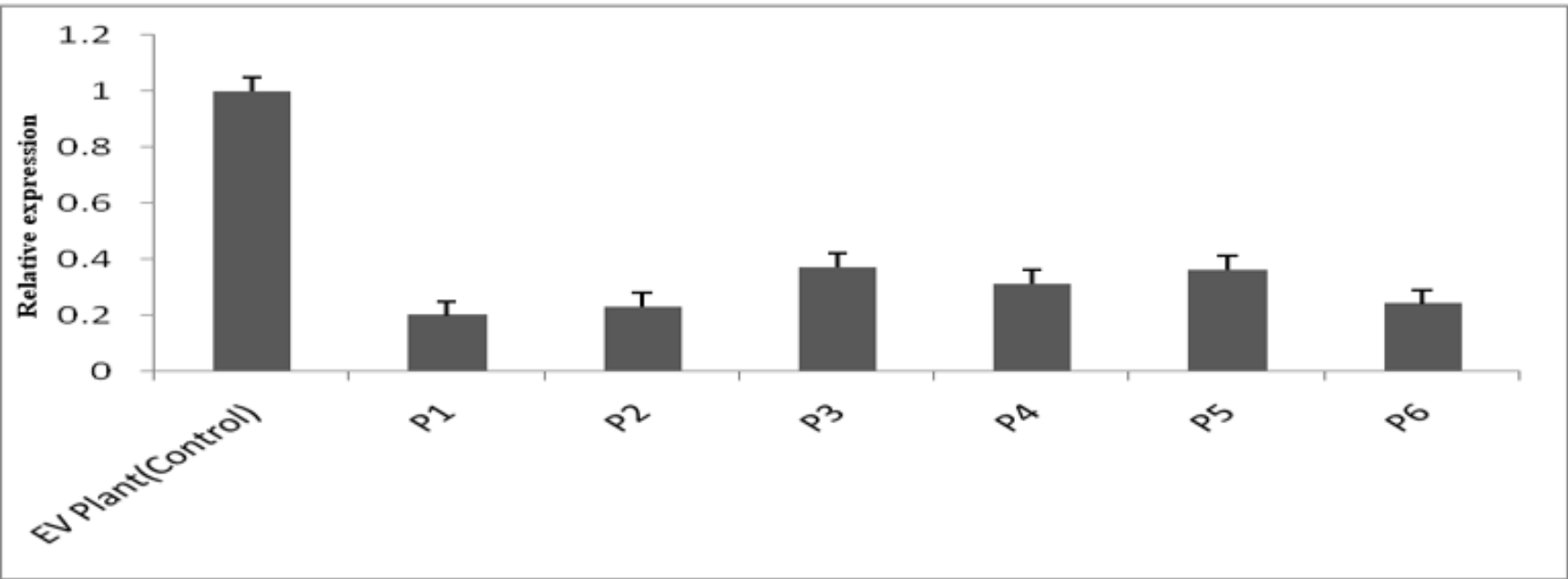

(b)

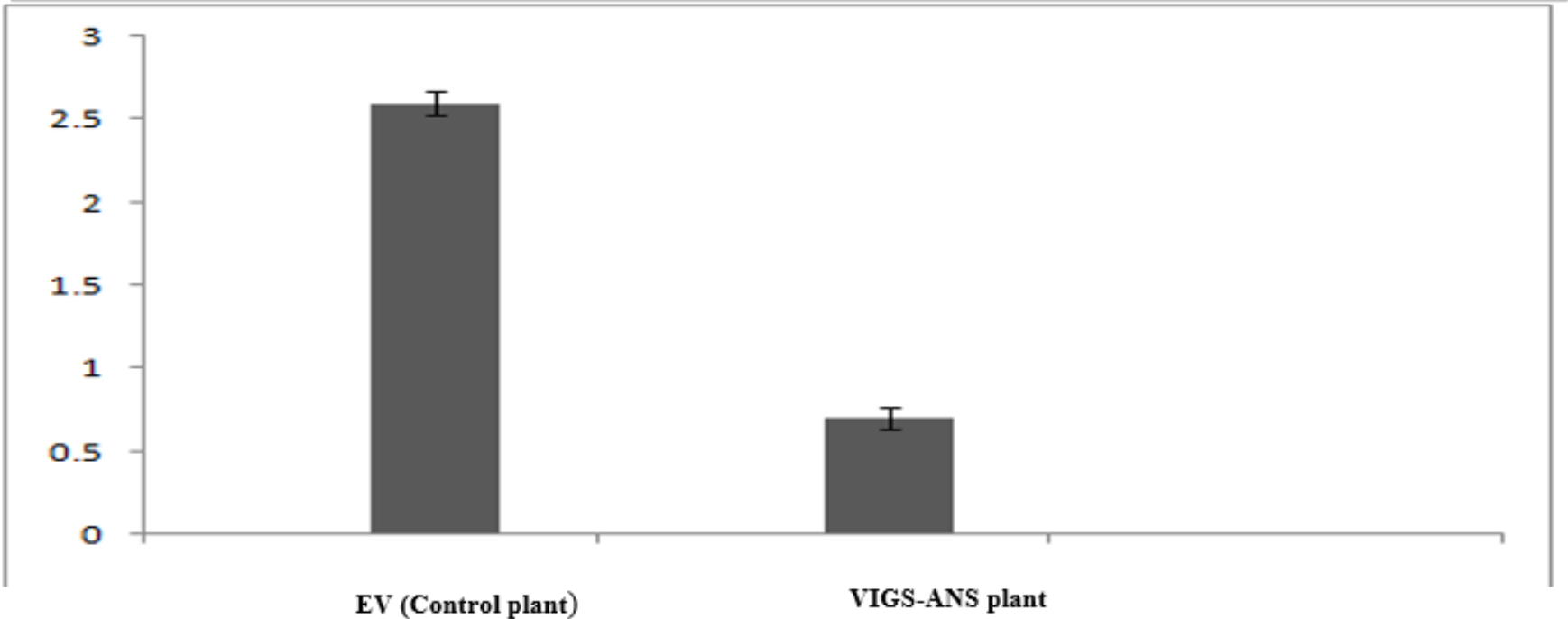

\section{Figure 5}

(a) Expression levels in leaves of Control plant (EV) and VIGS plants. Six silencing events were analyzed (1-6). Error bars represent mean \pm SD for three technical replicates for each. (b) Condensed tannin estimation through vanillin assay in control plant (EV) and VIGS-ANS plant of P.tetragonolobus. 
(a)

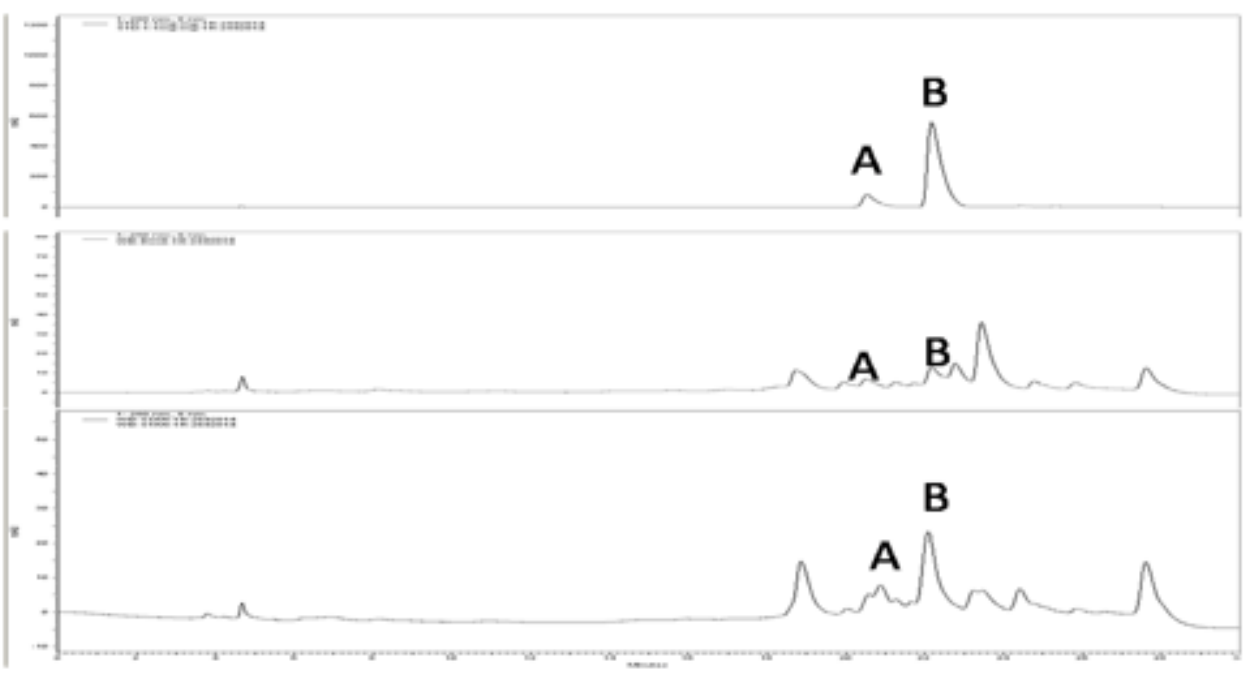

(b)

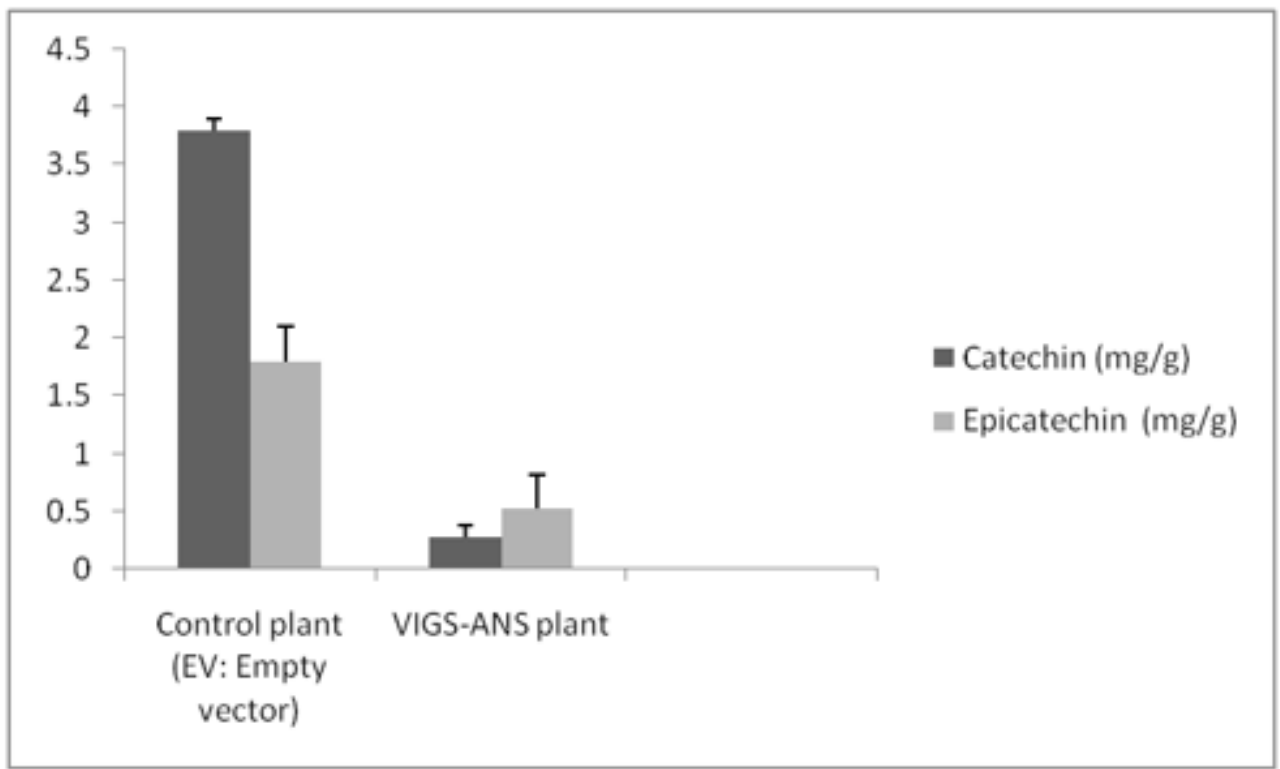

Standard

VIGS-ANS plant

Control plant

\section{Figure 6}

(a): chromatograms of HPLC analysis of leaf of VIGS and Control (EV) plant of Psophocarpous tetragonolobus with standards of $[A]$ catechin and $[B]$ epicatechin, (b) Quantification of condensed tannin in monomeric unit (Catechin and epicatechin) of leaf tissues of P.tetragonolobus through HPLC 
$\mathrm{OG}$

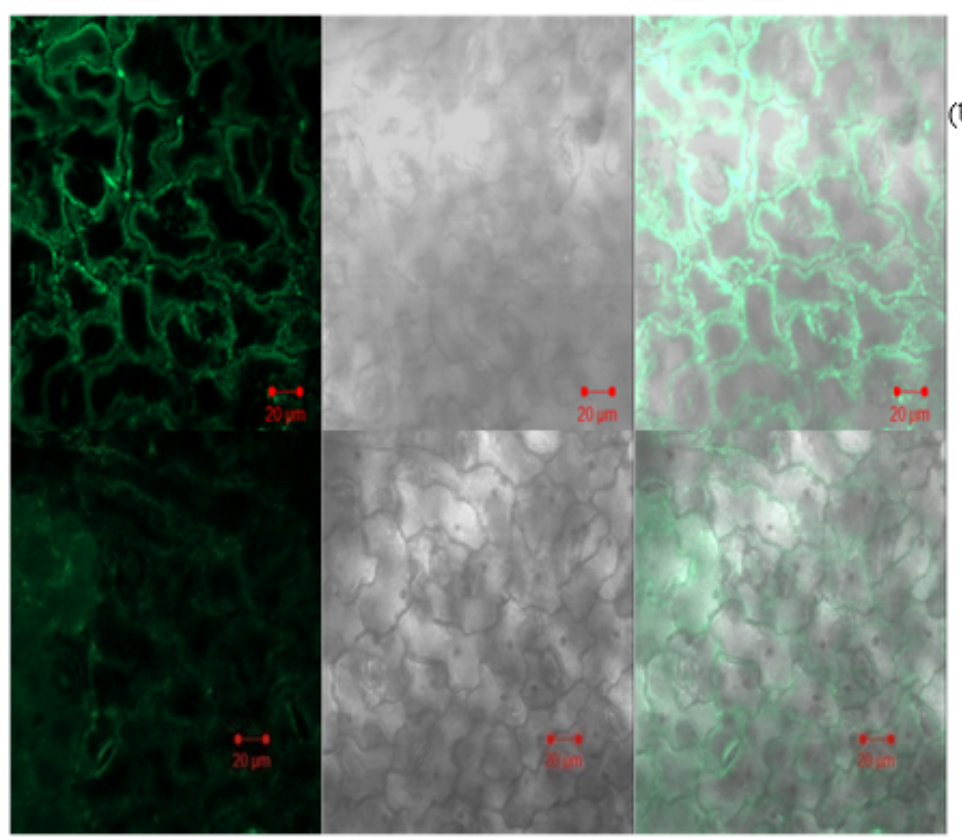

Merged (b)

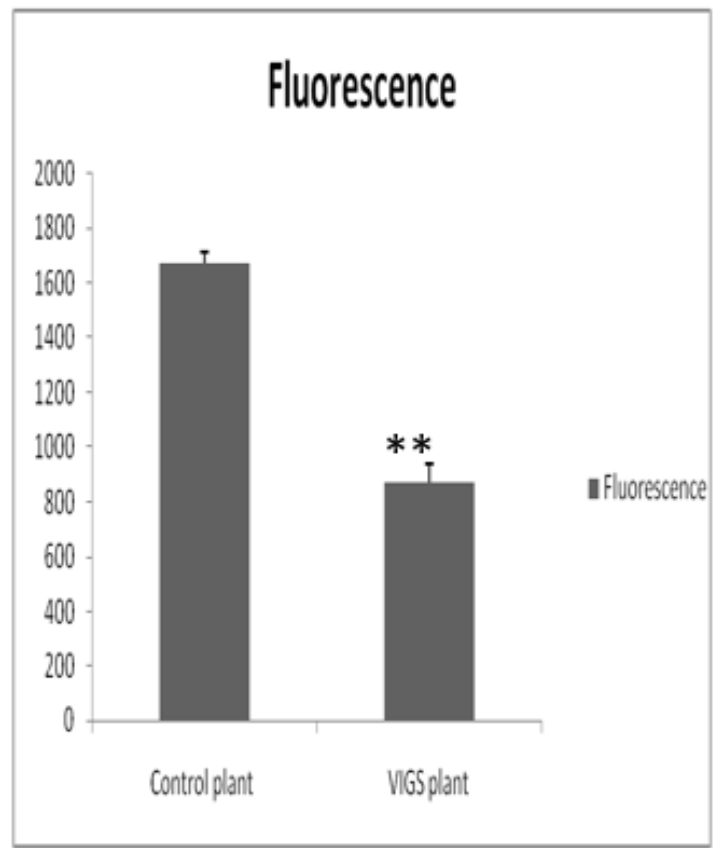

\section{Figure 7}

Confocol microscopy of Control vs VIGS plant: A-Oregon green staining in the leaf P.tetragonolobus in VIGS treated plant and control plant (20X magnifications on confocal microscope. Bars $=20 \mu \mathrm{m}$ ). Upper lane of image is Control plant and lower one is VIGS treated plant (1). OG: Oregon green stained (2) DIC and (3) merge of Oregon green and DIC (b) The degree of fluorescence calculated by IMAGE J software showed significant decrease in VIGS-ANS induced plant. 


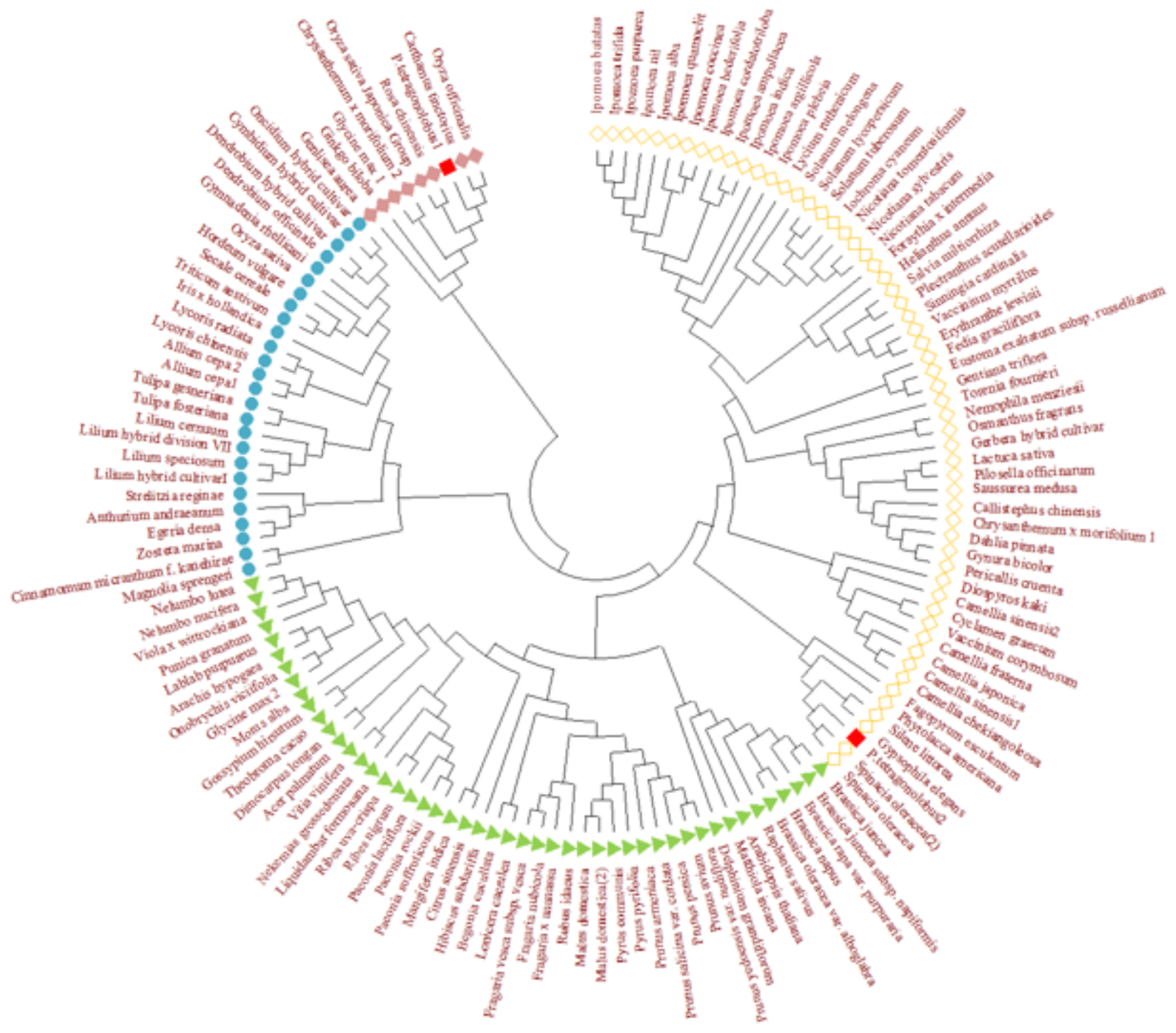

Figure 8

Phylogenetic analysis of Anthocyanidin synthase gene of two p.tetragonolobus sequence with NCBI data of anthocyanidin synthase through Mega 6 software

\section{Supplementary Files}

This is a list of supplementary files associated with this preprint. Click to download.

- SupplementaryTableS1.docx

- SupplementaryTableS2.docx 